\title{
Notes on the vocalizations of Square-tailed Black Bulbul (Hypsipetes ganeesa) and Himalayan Black Bulbul (Hypsipetes leucocephalus)
}

Peter Boesman

In the following we briefly analyze and compare voice of the different races of Square-tailed Black Bulbul (Hypsipetes ganeesa) and Himalayan Black Bulbul (Hypsipetes leucocephalus). We also try to quantify the extent of any vocal differences using the criteria proposed by Tobias et al. (2010), as a support for taxonomic review. We have made use of sound recordings available on-line from Xeno Canto (XC), Macaulay Library (ML).

This is quite a complex case, given the many subspecies. Most vocalization types are seemingly shared by many races. A quick overview:

\section{Overslurred nasal call}

\section{Sri Lanka}

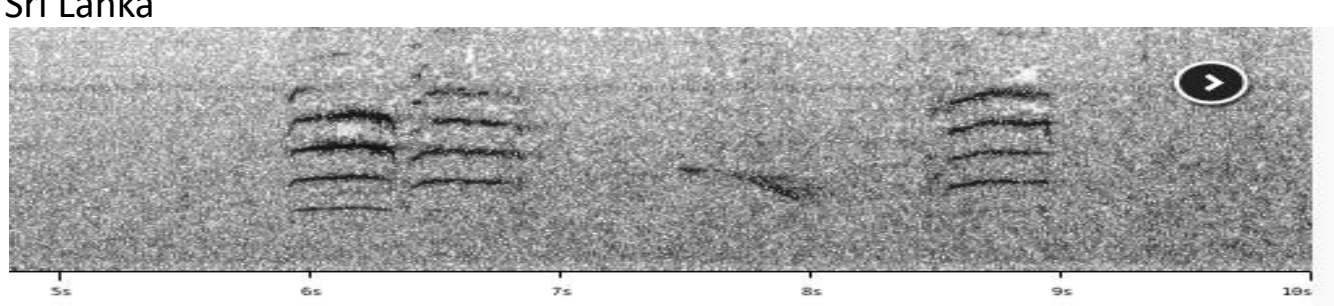

Thailand
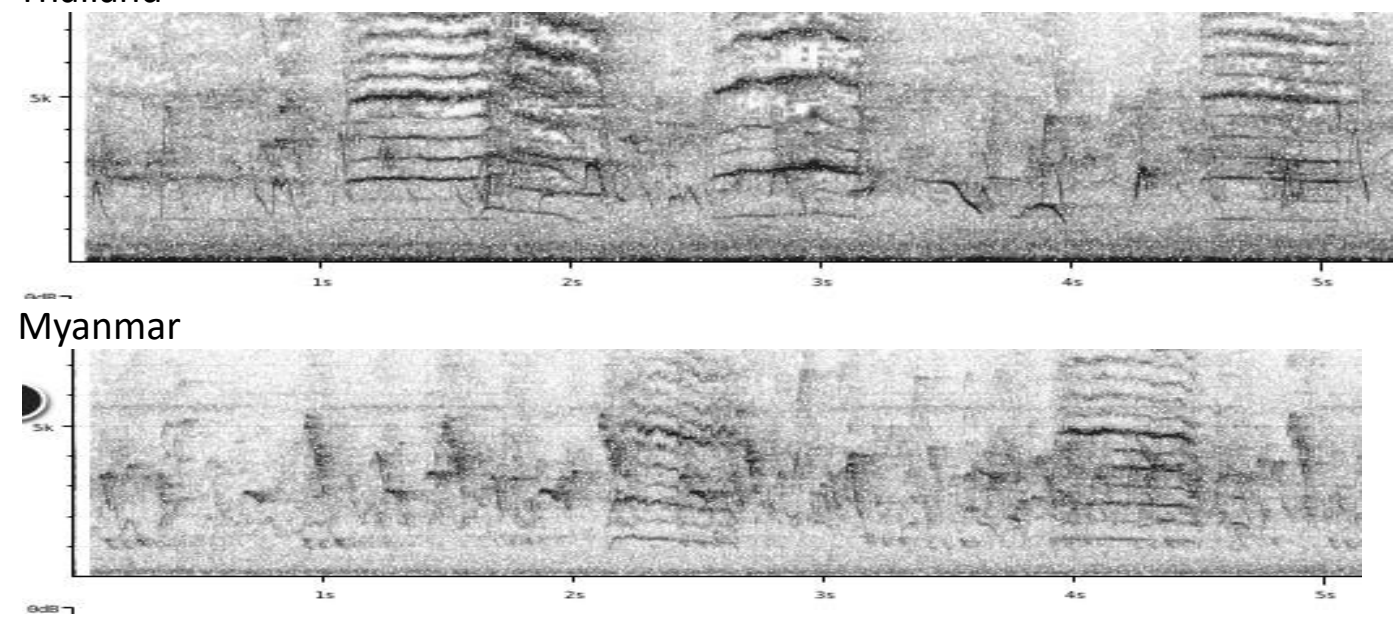

E China

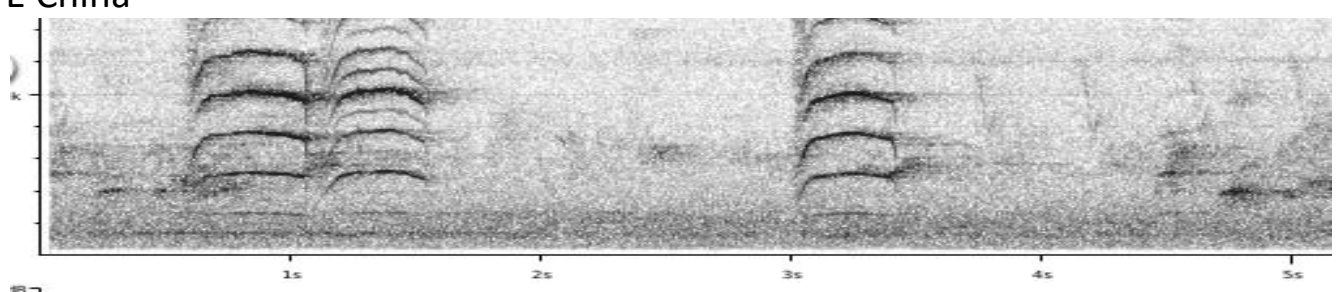




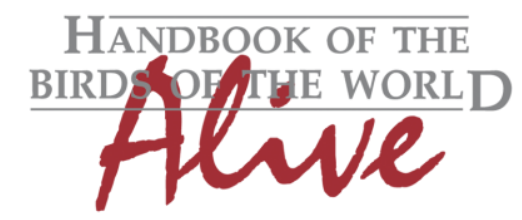

\section{ORNITHOLOGICAL NOTES}

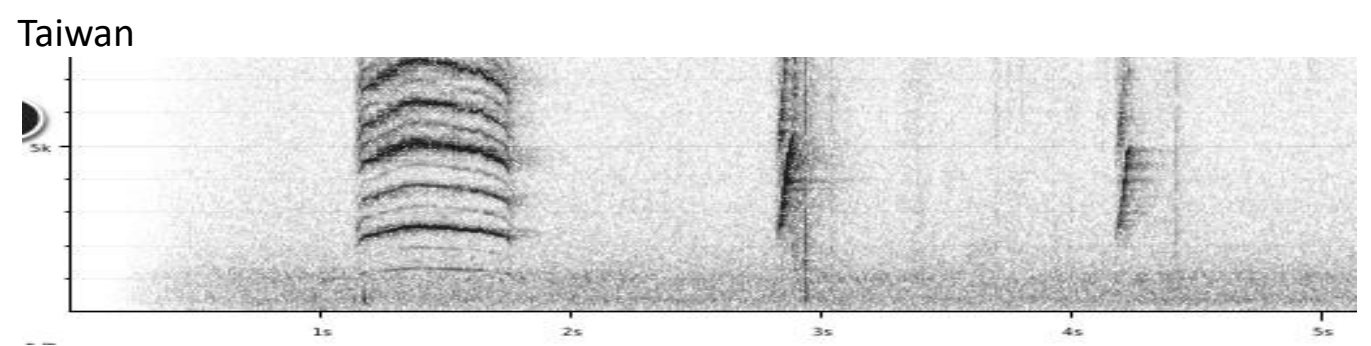

\section{$\underline{\text { 2. Decending nasal call }}$}

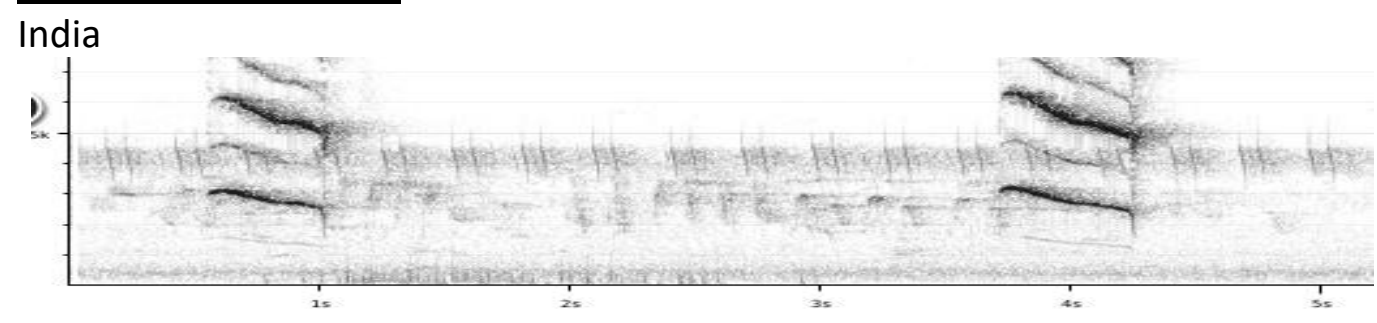

S China (Yunnan)
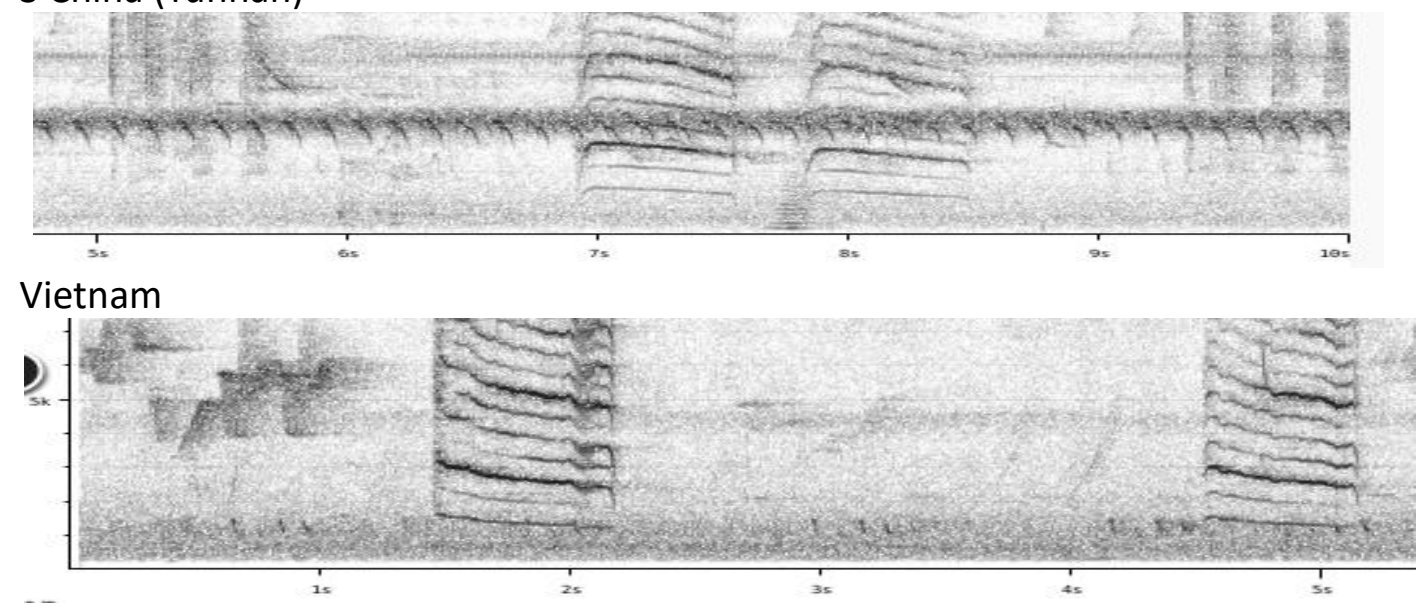

While there is a marked difference between e.g. the descending call of mainland India vs. the overslurred call of Sri Lanka, placed in a larger perspective it would seem that the picture is not clear-cut, with e.g. gradual transitions from S China over Thailand to Myanmar. There are apparently no recordings of this vocalization from India/Nepal/Bhutan in the Himalayas (psaroides) (although a voice description in the Ripley Guide suggests this call is also heard in Nepal (Rasmussen et al. 2012)).

\section{Other vocalizations}

Race ganeesa (SW India): Variations mainly based on short emphatic clear notes, rather staccato metallic sounding

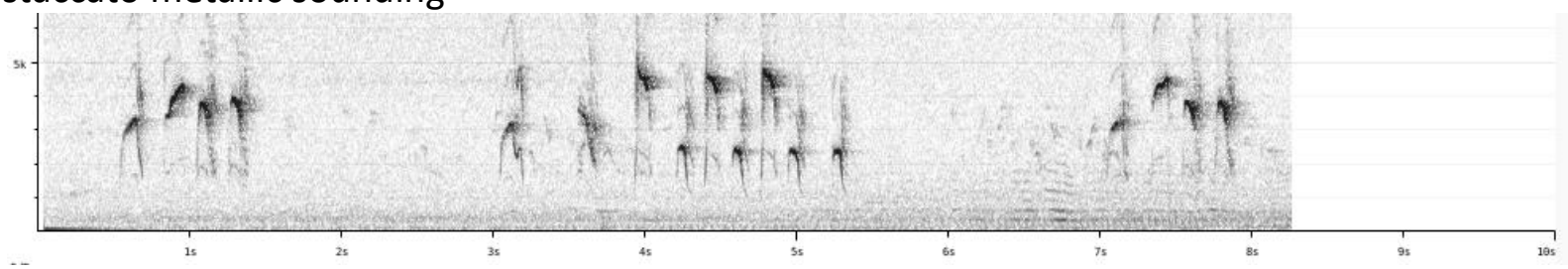


HANDBOOK OF THE

BIRDSPFGE WORLD

\section{ORNITHOLOGICAL NOTES}

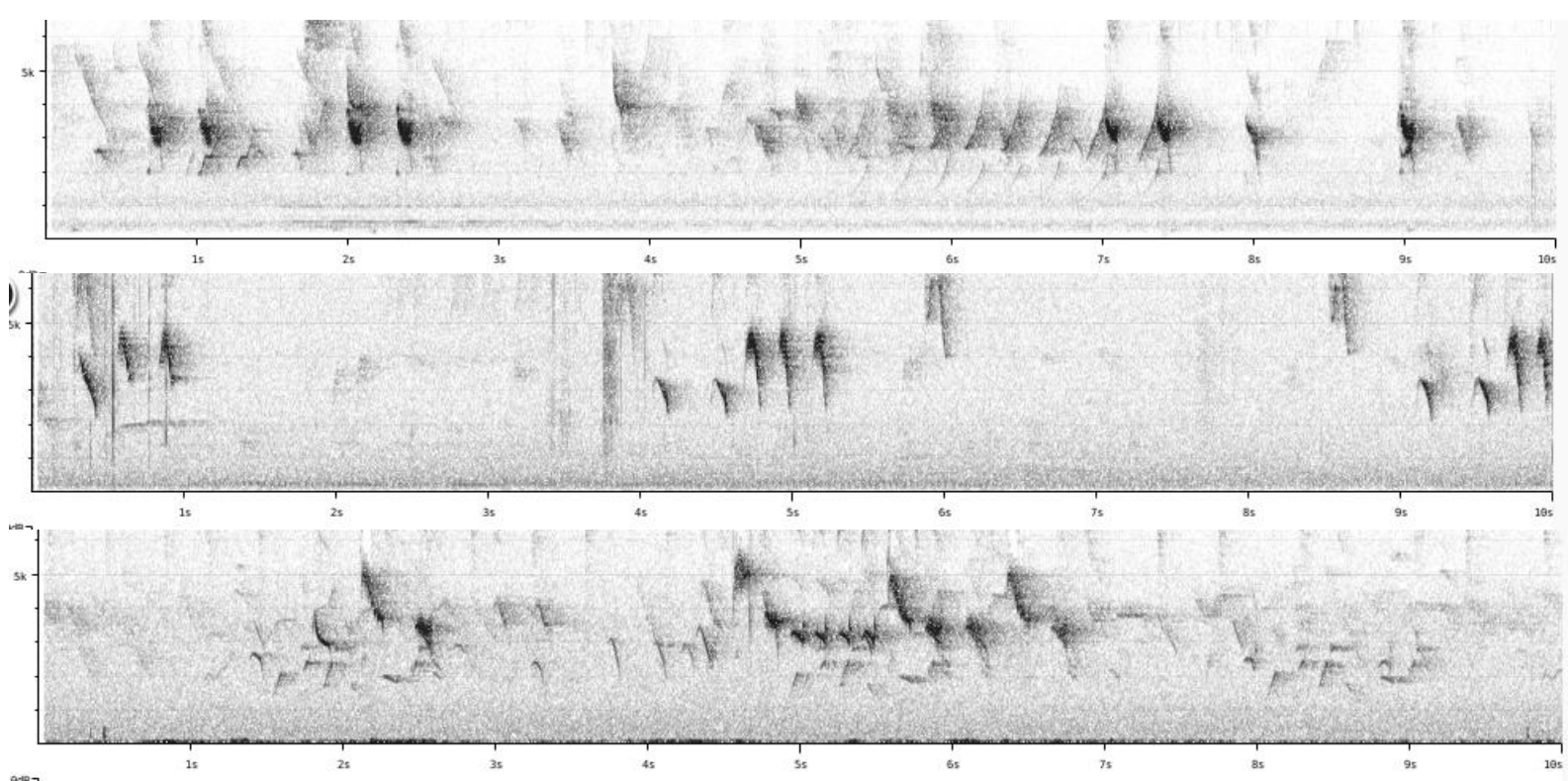

Race humii (Sri Lanka): Rather different vocalizations, mainly unmusical short phrases with many notes rather burry or guttural:

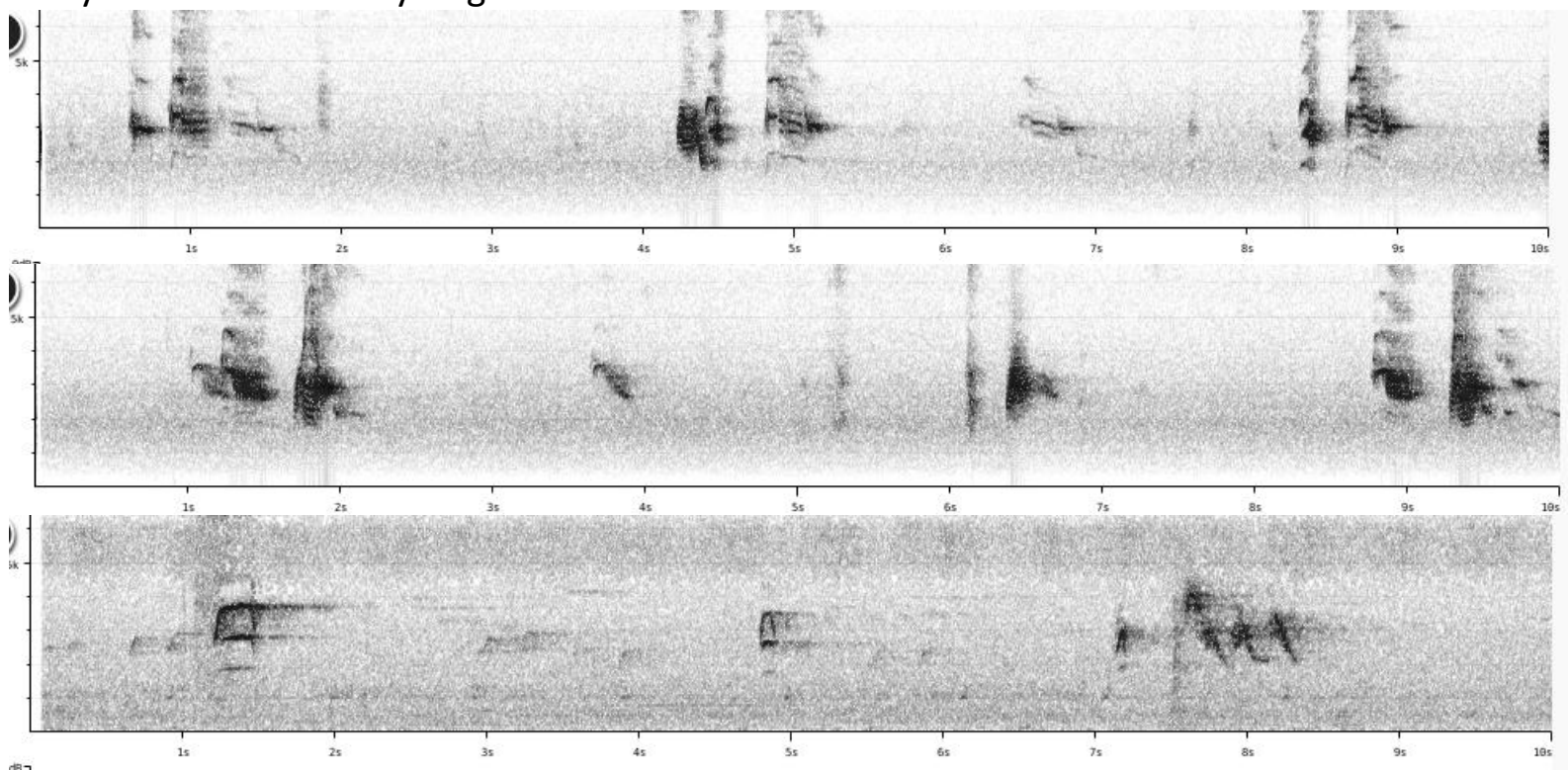

Other races have several calls similar (but not identical) to ganeesa:

Nepal

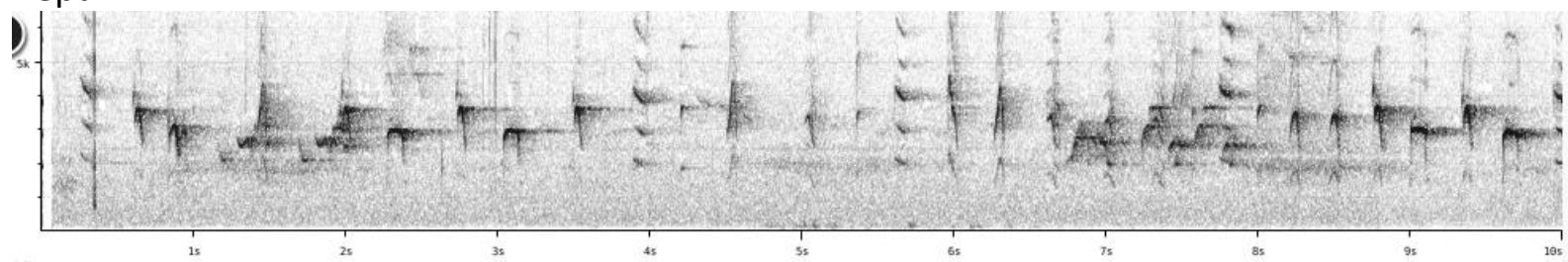

NE India

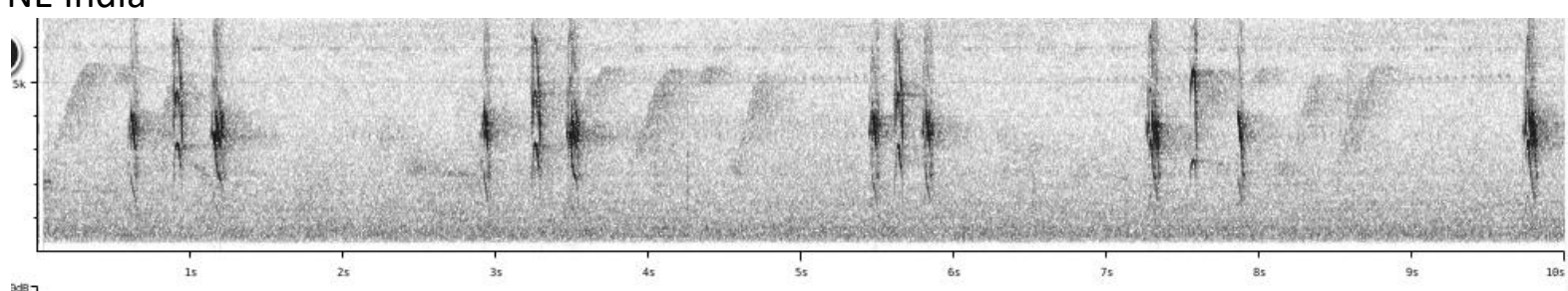




\section{HANDBOOK OF THE \\ BIRDS PF/THE WORLD}

\section{ORNITHOLOGICAL NOTES}

Thailand

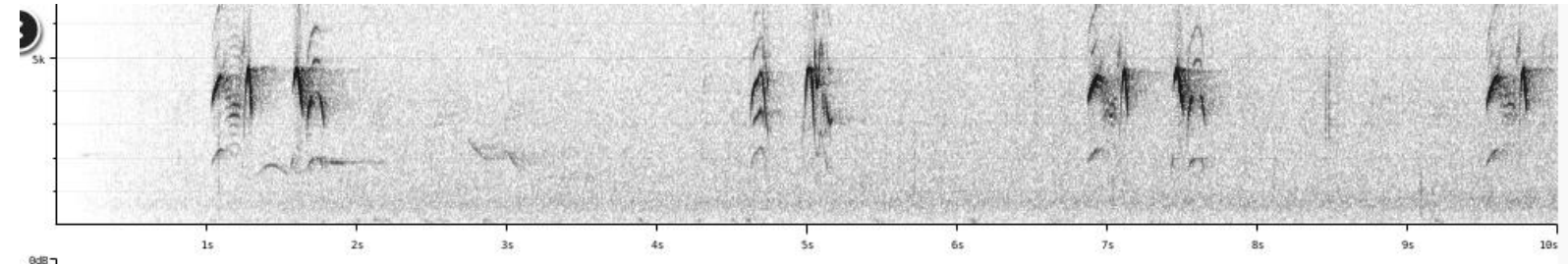

Vietnam
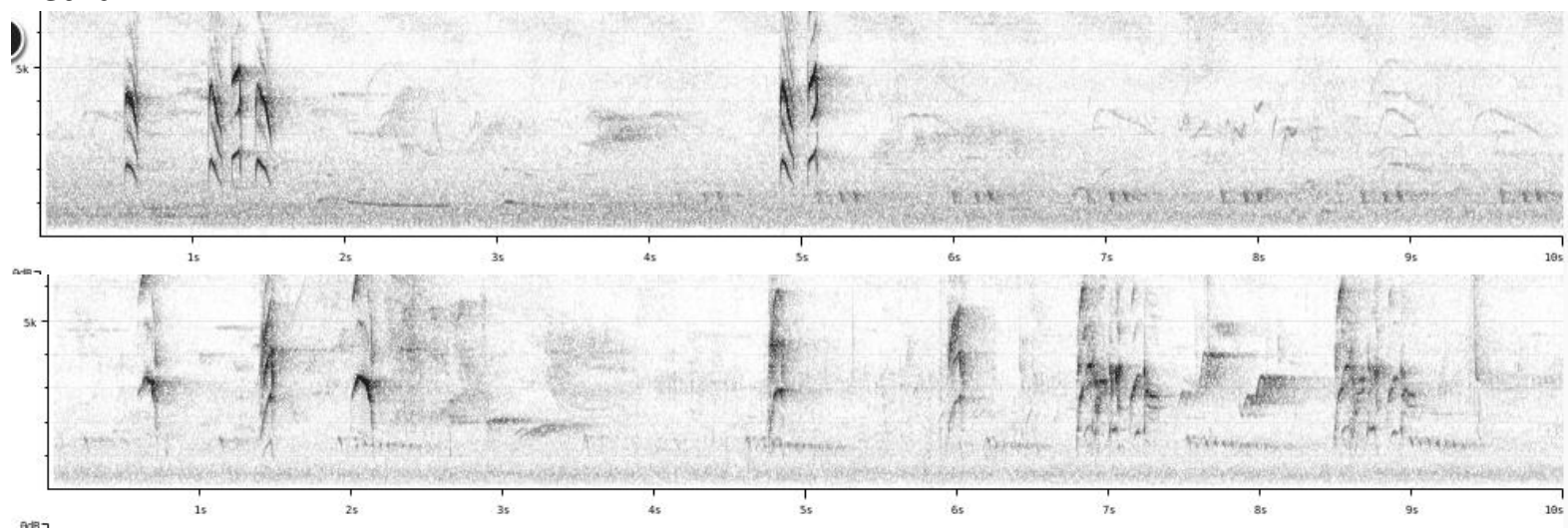

Furthermore, several races have short phrases with melodic notes at flat pitch mixed in:

\section{N India}

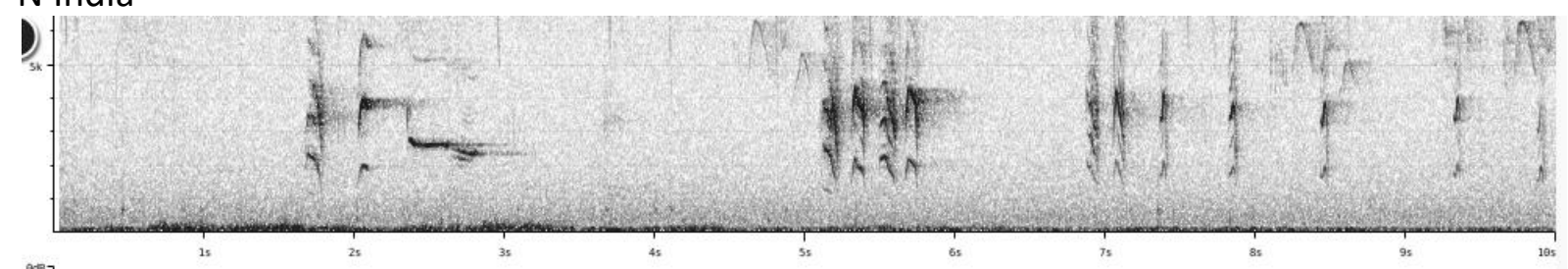

NE India

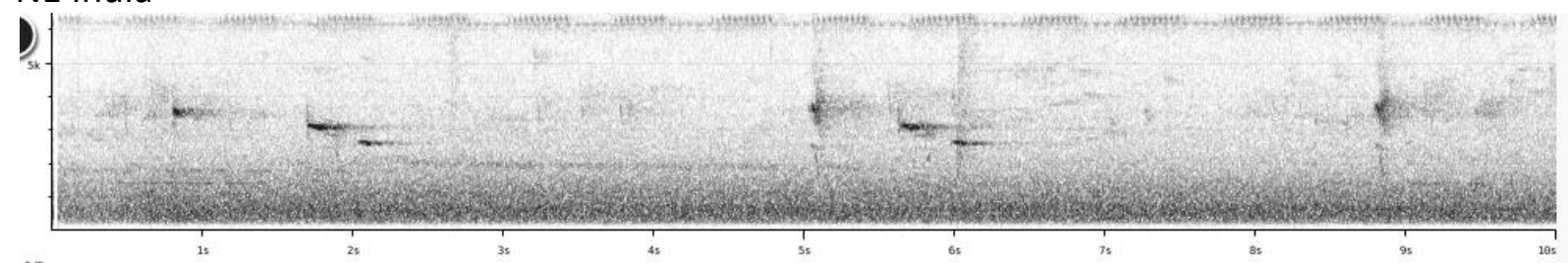

\section{China}

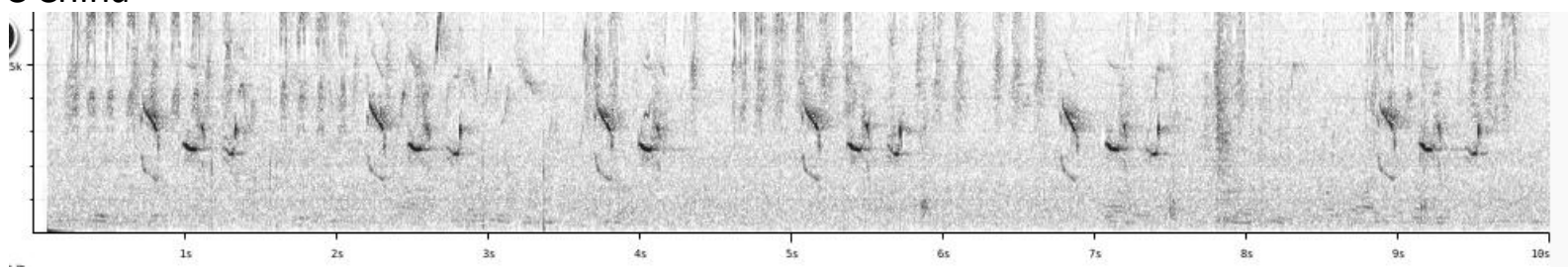

Taiwan

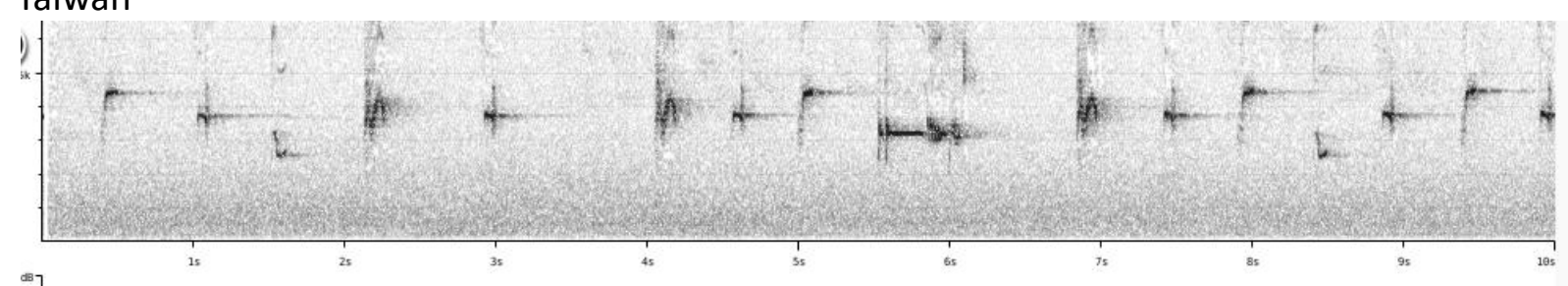



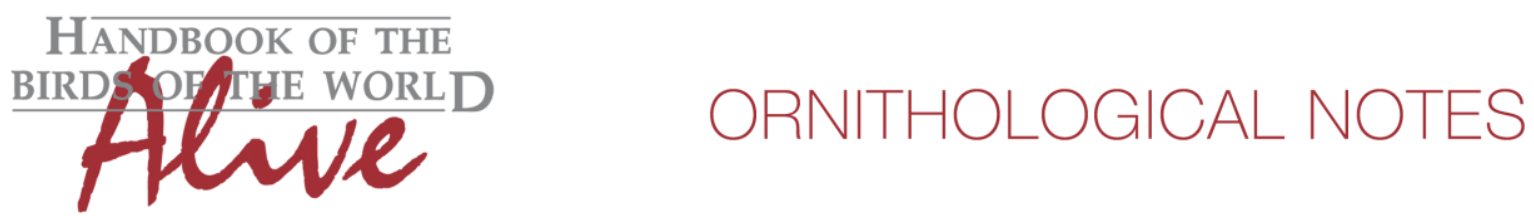

Based on the above, it would seem that vocally there are three distinct groups.

* the leucocephalus group

* ganeesa

* humii

While they all share drawn-out nasal screaming calls, they differ in their other vocalizations: humii has mainly unmusical short phrases with many notes rather burry or guttural (allow score 3). ganeesa shares with the leucocephalus group the general structure of short phrases, but the staccato overslurred notes are purer (much less energy in harmonics)(score 1 ), and ganeesa lacks the melodious song phrases with short sweet notes on flat pitch (score 1-2), while ganeesa has many pure downslurred notes in its vocabulary. Total vocal score compared to other races about 2-3.

This note was finalized on 21st February 2016, using sound recordings available on-line at that moment. We would like to thank in particular the many sound recordists who placed their recordings for this species on XC.

\section{References}

Rasmussen, P.C. \& Anderton, J.C. (2012). Birds of South Asia: the Ripley Guide. Lynx Edicions, Barcelona.

Tobias, J.A., Seddon, N., Spottiswoode, C.N., Pilgrim, J.D., Fishpool, L.D.C. \& Collar, N.J. (2010). Quantitative criteria for species delimitation. Ibis 152(4): 724-746.

\section{Recommended citation}

Boesman, P. (2016). Notes on the vocalizations of Square-tailed Black Bulbul (Hypsipetes ganeesa) and Himalayan Black Bulbul (Hypsipetes leucocephalus). HBW Alive Ornithological Note 244. In: Handbook of the Birds of the World Alive. Lynx Edicions, Barcelona. (retrieved from http://www.hbw.com/node/932241 on 30 September 2016). 